\title{
The need and challenges for development of an Epstein-Barr virus vaccine
}

\author{
Jeffrey I. Cohen ${ }^{a,}{ }^{,}$Edward S. Mocarski ${ }^{b}$, Nancy Raab-Traub ${ }^{c}$, Lawrence Corey ${ }^{d}$, and Gary \\ J. Nabel ${ }^{\mathrm{e}}$ \\ aLaboratory of Infectious Diseases, National Institute of Allergy and Infectious Diseases, National \\ Institute of Health, Bethesda, MD, USA \\ bepartment of Microbiology and Immunology, Emory Vaccine Center, Emory University School \\ of Medicine, Atlanta, GA, USA
}

'Lineberger Comprehensive Cancer Center and Department of Microbiology-Immunology, University of North Carolina, Chapel Hill, NC, USA

dFred Hutchinson Cancer Research Center, Seattle, WA, USA

eVaccine Research Center, National Institute of Allergy and Infectious Diseases, National Institutes of Health, Bethesda, MD, USA

\section{Abstract}

Epstein-Barr virus (EBV) is the major cause of infectious mononucleosis and is associated with several malignancies including nasopharyngeal carcinoma, gastric carcinoma, Hodgkin lymphoma, Burkitt lymphoma, and lymphoma after organ or stem cell transplant. A candidate vaccine containing soluble EBV glycoprotein gp350 protected cottontop tamarins from EBV lymphoma after challenge with EBV. In the only phase 2 trial of an EBV vaccine in humans, soluble gp350 in alum and monophosphoryl lipid A adjuvant reduced the rate of infectious mononucleosis in EBV seronegative adults, but did not affect the rate of EBV infection. A peptide vaccine corresponding to EBV latency proteins has been tested in a small number of adults to prevent infectious mononucleosis. Some of the barriers to development of an EBV vaccine include (a) whether additional viral proteins in addition to gp350 would be more effective for preventing mononucleosis or EBV malignancies, (b) the difficulty of performing clinical trials to prevent EBV associated malignancies in the absence of good surrogate markers for tumor development, and the long period of time between primary EBV infection and development of many EBV tumors, (c) the lack of knowledge of immune correlates for protection against EBV infection and disease, (d) the limitations in animal models to study protection against EBV infection and disease, and (e) the need for additional information on the economic and societal burden of infectious mononucleosis to assess the cost-benefit of a prophylactic vaccine.

(C) 2012 Published by Elsevier Ltd.

"Corresponding author at: Bldg. 50, Rm. 6134, National Institutes of Health, 50 South Drive, MSC 8007, Bethesda, MD 20892, USA. Tel.: +1 301496 5265; fax: +1 301496 8312. jcohen@ niaid.nih.gov (J.I. Cohen).

Edward Mocarski is a paid consultant in the area of EBV vaccines for MedImmune, LLC. The other authors do not have conflicts of interest.

Lawrence Corey holds shares in Immune Design Corporation which has supplied an adjuvant which may be used in a candidate EBV vaccine developed by MedImmune, LLC.

Publisher's Disclaimer: This is a PDF file of an unedited manuscript that has been accepted for publication. As a service to our customers we are providing this early version of the manuscript. The manuscript will undergo copyediting, typesetting, and review of the resulting proof before it is published in its final citable form. Please note that during the production process errors may be discovered which could affect the content, and all legal disclaimers that apply to the journal pertain. 


\section{Keywords}

Epstein-Barr virus; infectious mononucleosis; nasopharyngeal carcinoma; Burkitt lymphoma; gastric carcinoma; Hodgkin lymphoma

\section{BACKGROUND}

Epstein-Barr virus (EBV) causes over $90 \%$ of cases of infectious mononucleosis (IM) in developed countries [1] with cytomegalovirus as the second most common cause. EBV is usually spread from oral secretions and the virus infects resting B cells in the oropharynx or epithelial cells which in turn infect B cells. Infection early in life is usually asymptomatic or results in nonspecific symptoms, while infection of adolescents or young adults can result in IM. IM is usually a self-limited disease that presents with fever, pharyngitis, and lymphadenopathy. Most studies state that between 25\% to 50\% of adolescents and young adults in developed countries present with IM if infected with EBV. However, a recent study followed EBV seronegative college students prospectively for symptoms of IM and reported that $>75 \%$ of confirmed primary EBV infections were associated with IM [2]. There are approximately 125,000 new cases of IM each year in the United States. Although most cases of IM resolve within one month, nearly $10 \%$ of patients have fatigue that persists for 6 or more months. About $1 \%$ of EBV infections result in severe complications including encephalitis, hepatitis, severe hemolytic anemia or thrombocytopenia.

EBV is also associated with several malignancies. Each year worldwide it is estimated that there are about 84,000 cases of EBV-associated gastric carcinomas, 78,000 cases of EBVassociated nasopharyngeal carcinoma, and 28,000 cases of EBV-associated Hodgkin lymphoma [3,4]. The risk of EBV-positive Hodgkin disease peaks at 4 years after IM, and the risk decreases to normal after 10 years [5]. The rate of nasopharyngeal carcinoma is estimated to be 50 per 100,000 in men > 50 years of age in Southern China [6].

Nasopharyngeal carcinoma is also more common in Northern Africa, and in Inuit populations in the Arctic. In less developed countries, there are over 6,000 cases of EBVassociated Burkitt lymphoma each year. EBV-associated Burkitt lymphoma is most common in equatorial Africa and New Guinea. In equatorial Africa the rate of Burkitt lymphoma is 20 cases per 100,000 in children between the ages of 5 and 9 [7]. EBV is also associated with other malignancies including nasal NK/T cell lymphomas and peripheral $\mathrm{T}$ cell lymphomas.

EBV is also associated with malignancies in immunocompromised patients. EBV lymphoma is second only to skin cancer as the most common malignancy after organ transplantation. While the rates of many AIDS-associated malignancies have been declining with the use of highly active anti-retroviral therapy, the rates of rates of EBV-positive Burkitt and Hodgkin lymphoma in this population have not declined.

EBV is highly species specific and only infects humans. Initial studies of EBV vaccines used cottontop tamarins, now an endangered species, which are highly susceptible to EBV lymphomas apparently due to a less diverse MHC gene repertoire that might limit the host immune response to virus-transformed cells. Vaccination with the major viral glycoprotein, gp350, protected animals from development of EBV B cell lymphomas after parenteral challenge [8]. Subsequent experiments used virus vectors expressing EBV gp350 which were also effective. This model has several caveats including the very high doses of EBV in the challenge inoculum required to cause tumors, a non-physiologic route of infection (intraperitoneal injection of virus), and the fact the EBV is not a natural pathogen in these 
animals. EBV vaccine studies have also been performed in common marmosets and EBV gp350 can protect against parenteral challenge of these animals [9].

Rhesus macaques are naturally infected with rhesus lymphocryptovirus, which has homologs for each of the genes in EBV [10]. Infection of macaques with rhesus lymphocryptovirus reproduces most, if not all, the features of EBV seen in humans [11]. Animals become latently infected, shed the virus for long periods of time, and if immunosuppressed can develop EBV associated malignancies. A recent study compared three different vaccines in these animals- (a) soluble gp350, (b) virus-like replicon particles expressing gp350, and (c) a combination of virus-like replicon particles expressing gp350 and the EBV latency proteins EBNA-3A and EBNA-3B [12]. Vaccination with soluble gp350 protected the animals from infection after oral challenge, and resulted in the lowest level of viral DNA in the blood of animals two years after they had become infected with the challenge virus.

Very few EBV vaccine trials have been performed in humans to prevent infection or IM. Vaccinia virus expressing EBV gp350 was given to nine seronegative children in China and at 16 months one-third of vaccinees had become infected with the virus compared with $100 \%$ of unvaccinated controls [13]. In the only phase 2 trial of an EBV vaccine, of 181 seronegative adults who were randomized to receive soluble EBV gp350 in alum and monophosphoryl lipid A or placebo, those receiving the vaccine had a $78 \%$ reduction in the rate of IM, but no difference in the rate of infection [14]. A study of an HLA B0801restricted CD8 $\mathrm{T}$ cell peptide epitope vaccine corresponding to an EBV latency protein (EBNA-3A) in four HLA B0801-positive, EBV seronegative vaccinees showed that all four became infected with EBV without developing IM, while one of two placebo recipients developed IM [15].

A vaccine to prevent IM would likely be used in preadolescent children (ages 11-12) in developed countries around the same time as the current human papillomavirus vaccine is given [16]. In contrast, a vaccine to prevent EBV-associated malignancies in developing countries, such as to prevent Burkitt lymphoma would need to be given very early in childhood.

\section{BARRIERS/PROBLEMS}

While EBV gp350 appears to be a valid immunogen for a vaccine to prevent IM, it is unknown whether a vaccine with additional EBV antigens might be more effective in preventing IM or virus infection. EBV encodes a number of other glycoproteins that elicit neutralizing antibodies. EBV also encodes a very large number of proteins that are targets of CD4 and CD8 T cells [17]. It is not clear what additional viral proteins would be needed for a vaccine to prevent EBV-associated malignancies. The likely candidates are EBV proteins expressed in these malignancies (EBV latent membrane proteins 1 and 2 [LMP1, LMP2) and EBV nuclear antigens 1, 2, 3 (EBNA-1-3). At present the correlates of protection against EBV malignancy are unknown.

Clinical trials to prevent EBV-associated malignancies would be difficult as there are not good surrogate markers for development of these tumors. The best biomarkers for an EBV malignancy are for nasopharyngeal carcinoma where the development of IgA to EBV VCA or EBV DNAse in serum or saliva correlates with an increased risk of disease; the relative risk of developing nasopharyngeal carcinoma was 22 for subjects who were EBV IgA VCA antibody positive versus those who were EBV VCA IgA negative [18]. EBV IgA antibody levels are elevated up to a decade prior to the diagnosis of nasopharyngeal carcinoma [19]. Patients at risk for EBV lymphoproliferative disease and those with nasopharyngeal carcinoma often have elevated EBV DNA in the blood. 
EBV-associated nasopharyngeal carcinoma and gastric carcinoma, the two most common virus-associated malignancies, peak by age $>50$ years and it would be impractical to observe patients for $>30$ years to assess the impact of vaccination. EBV-associated Burkitt lymphoma is a disease of young children; however, EBV infection in developing countries where the disease is endemic occurs at a very early age and often when there is still maternal antibody to EBV. Even in these areas, a very large number of children would need to be vaccinated to determine if the vaccine were to prevent lymphoma.

The potential for an EBV vaccine to prevent malignancy could be more readily evaluated in transplant recipients, particularly seronegative children. Immunization of seronegative transplant recipients, before transplantation could determine if vaccination reduces the incidence of transplant related lymphoma or the use of rituximab therapy (currently given when EBV DNA rises in the blood which can occur before the onset of EBV lymphoma). One concern with this idea is that, these patients often have organ disease and may be less responsive to vaccinations. A small clinical trial of EBV gp350 in children with chronic renal disease found that the immune response to the vaccine waned very rapidly [20]; however, the dose of vaccine and the adjuvant were likely not optimal.

Animal models to test EBV vaccines for their ability to protect against infection and disease are very limited, since EBV does not naturally infect other animals. While high doses of EBV can cause tumors in cottontop tamarins, this is not a practical model as these animals are an endangered species. Reconstitution of severely immunocompromised mice with a human immune system might be used as a model, but the new human immune system might not have all the features of a normal immune response; for example, EBV interacts with several cellular proteins to evade the immune response and it is unclear whether these proteins would have the same properties in a humanized mouse.

While the EBV gp350 vaccine was first shown to protect animals from EBV lymphomas in 1985 , there has been relatively little interest in developing this vaccine for protection of humans now $>25$ years later. Only one phase 2 trial EBV vaccine trial has been performed. Importantly, the EBV gp350 vaccine reduced the rate of development of IM, but did not block virus infection. There is a real need to obtain further information on the economic and societal burden of IM, to determine whether such a vaccine would be viable for development by a company. Since only a single EBV vaccine has ever been tested in a phase 2 trial, it is unknown if there would be enhanced protection against EBV disease with the inclusion of viral proteins in addition to gp350 to a vaccine.

\section{CONCRETE ACTIONS/RECOMMENDATIONS}

A recent meeting at the National Institutes of Health proposed a number of recommendations for future research and EBV vaccine studies [21]. Some of these are outlined below.

- There is a need to determine the burden of IM in developed countries.

Epidemiologic studies should be performed to better determine the cost-benefit of a prophylactic vaccine for IM.

- A phase 3 study of gp350, with or without additional viral proteins, should be performed to determine for certain if gp350 definitively reduces the rate of IM in larger population, and if the vaccine is safe. These studies should also follow vaccinated patients long term to evaluate the level of EBV DNA in the blood, a marker of control of EBV infection, and compare this level with that in placebo recipients. A recent study reported that higher levels of EBV DNA in the blood of 
persons with IM were associated with more severe disease [2]. Early phase clinical trials are needed for other EBV vaccine candidates.

- More information is needed on surrogate markers to predict development of EBV associated malignancies in addition to nasopharyngeal carcinoma. Surrogate markers were essential in early studies of hepatitis B and human papillomavirus vaccines, and identification of similar makers for EBV malignancies would make clinical trials more practical and likely increase interest by vaccine manufacturers.

- Additional animal models for EBV IM and malignancy would allow more effective preclinical vaccine development.

- Additional information is needed on immune correlates for an EBV vaccine. While a large number of viral proteins are targets of CD4 and CD8 T cells in healthy persons, it is not known which of these correlate with protection from EBV diseases.

- While prevention of infection is ideal, prevention of EBV disease would be a useful goal for an EBV vaccine. Although persons have multiple exposures to EBV and may be infected with multiple strains of virus, IM only occurs once if at all in each individual. A vaccine that protects against disease, but not infection might be useful, as evidenced by the only licensed herpesvirus vaccine in humans, the varicella vaccine, which does not prevent infection.

\section{Acknowledgments}

Jeffrey Cohen is supported by the intramural research program of the National Institute of Allergy and Infectious Diseases.

\section{Abbreviations}

$\begin{array}{ll}\text { EBV } & \text { Epstein-Barr virus } \\ \text { IM } & \text { infectious mononucleosis } \\ \text { LMP } & \text { latent membrane protein } \\ \text { EBNA } & \text { EBV nuclear antigen }\end{array}$

\section{References}

1. Cohen JI. Epstein-Barr virus infection. N Engl J Med. 2000; 343:481-492. [PubMed: 10944566]

2. Balfour HH, Odumade OA, Schmeling DO, Mullan BD, Ed JA, Knight JA, Vezina HE, Thomas W, Hogquist KA. Behavior, virologic, and immunologic factors associated with acquisition and severity of primary Epstein-Barr virus infection in university students. J Infect Dis. 2012 in press.

3. Fukayama M. Epstein-Barr virus and gastric carcinoma. Pathol Int. 2010; 60:337-350. [PubMed: 20518883]

4. Parkin DM. The global burden of infection-associated cancers in the year 2002. Int J Cancer. 2006; 118:3030-3044. [PubMed: 16404738]

5. Hjalgrim H, Askling J, Rostgaard K, Hamilton-Dutoit S, Frisch M, Zhang JS, Madsen M, Rosdahl N, Konradsen HB, Storm HH, Melbye M. Characteristics of Hodgkin's lymphoma after infectious mononucleosis. N Engl J Med. 2003; 349:1324-32. [PubMed: 14523140]

6. de-The, G. Nasopharyngeal carcinoma. In: Evans, AS.; Kaslow, RA., editors. Viral Infections of Humans:Epidemiology and Control. New York: Plenum Medical Book Co; 1997. p. 935-967.

7. Evans, AS.; Mueller, NS. Epstein-Barr Virus and Malignant Lymphomas. In: Evans, AS.; Kaslow, RA., editors. Viral Infections of Humans:Epidemiology and Control. New York: Plenum Medical Book Co; 1997. p. 895-933. 
8. Epstein MA, Morgan AJ, Finerty S, Randle BJ, Kirkwood JK. Protection of cottontop tamarins against Epstein-Barr virus-induced malignant lymphoma by a prototype subunit vaccine. Nature. 1985; 318:287-9. [PubMed: 2999604]

9. Emini EA, Schleif WA, Silberklang M, Lehman D, Ellis RW. Vero cell-expressed Epstein- Barr virus (EBV) gp350/220 protects marmosets from EBV challenge. J Med Virol. 1989 Feb; 27(2): 120-3. [PubMed: 2537882]

10. Rivailler P, Jiang H, Cho YG, Quink C, Wang F. Complete nucleotide sequence of the rhesus lymphocryptovirus: genetic validation for an Epstein-Barr virus animal model. J Virol. 2002; 76:421-6. [PubMed: 11739708]

11. Moghaddam A, Rosenzweig M, Lee-Parritz D, Annis B, Johnson RP, Wang F. An animal model for acute and persistent Epstein-Barr virus infection. Science. 1997; 276:2030-3. [PubMed: 9197263]

12. Sashihara J, Hoshino Y, Bowman JJ, Krogmann T, Burbelo PD, Coffield M, Kamrud K, Cohen JI. Soluble rhesus lymphocryptovirus gp 350 protects against infection and reduces viral loads in animals that become infected with virus after Challenge. PLoS Pathogens. 7(10):e1002308.10.1371/journal.ppat.1002308 [PubMed: 22028652]

13. Gu SY, Huang TM, Ruan L, Miao YH, Lu H, Chu CM, Motz M, Wolf H. First EBV vaccine trial in humans using recombinant vaccinia virus expressing the major membrane antigen. Dev Biol Stand. 1995; 84:171-177. [PubMed: 7796951]

14. Sokal EM, Hoppenbrouwers K, Vandermeulen C, Moutschen M, Léonard P, Moreels A, Haumont M, Bollen A, Smets F, Denis M. Recombinant gp350 vaccine for infectious mononucleosis: a phase 2, randomized, double-blind, placebo-controlled trial to evaluate the safety, immunogenicity, and efficacy of an Epstein-Barr virus vaccine in healthy young adults. J Infect Dis. 2007; 196:1749-1753. [PubMed: 18190254]

15. Elliott SL, Suhrbier A, Miles JJ, Lawrence G, Pye SJ, Le TT, Rosenstengel A, Nguyen T, Allworth A, Burrows SR, Cox J, Pye D, Moss DJ, Bharadwaj M. Phase I trial of a CD8+ T-cell peptide epitope-based vaccine for infectious mononucleosis. J Virol. 2008; 82:1448-1457. [PubMed: 18032491]

16. Stratton, KR.; Durch, JS.; Lawrence, RS. Vaccines for the $2^{1 \text { st }}$ Century: A Tool for Decision Making. Washington, DC: The National Academy Press; 2000.

17. Hislop AD, Taylor GS, Sauce D, Rickinson AB. Cellular responses to viral infection in humans: lessons from Epstein-Barr virus. Annu Rev Immunol. 2007; 25:587-617. [PubMed: 17378764]

18. Chien YC, Chen JY, Liu MY, Yang HI, Hsu MM, Chen CJ, Yang CS. Serologic markers of Epstein-Barr virus infection and nasopharyngeal carcinoma in Taiwanese men. N Engl J Med. 2001; 345:1877-82. [PubMed: 11756578]

19. Ji MF, Wang DK, Yu YL, Guo YQ, Liang JS, Cheng WM, Zong YS, Chan KH, Ng SP, Wei WI, Chua DT, Sham JS, Ng MH. Sustained elevation of Epstein-Barr virus antibody levels preceding clinical onset of nasopharyngeal carcinoma. Br J Cancer. 2007; 96:623-30. [PubMed: 17285127]

20. Rees L, Tizard EJ, Morgan AJ, Cubitt WD, Finerty S, Oyewole-Eletu TA, Owen K, Royed C, Stevens SJ, Shroff RC, Tanday MK, Wilson AD, Middeldorp JM, Amlot PL, Steven NM. A phase I trial of Epstein-Barr virus gp350 vaccine for children with chronic kidney disease awaiting transplantation. Transplantation. 2009; 88:1025-9. [PubMed: 19855249]

21. Cohen JI, Fauci AS, Varmus H, Nabel GJ. Epstein-Barr virus: an important vaccine target for cancer prevention. Sci Transl Med. 2011; 3(107):107fs7. 


\section{Highlights}

EBV results in over 120,000 cases of infectious mononucleosis in the US each year. EBV is associated with about 200,000 cases of cancer worldwide each year.

An EBV subunit vaccine reduced the rate of infectious mononucleosis in a trial.

More information is needed on surrogate markers to predict EBV associated cancers.

Further studies are needed to identify immune correlates for an EBV vaccine. 